\title{
The role of family and personal psychiatric history in postconcussion syndrome following sport-related concussion: a story of compounding risk
}

\author{
Andrew D. Legarreta, BA, ${ }^{1}$ Benjamin L. Brett, MS,1-3 Gary S. Solomon, $\mathrm{PhD},{ }^{1,4}$ and \\ Scott L. Zuckerman, MD, MPH ${ }^{1,4}$
}

${ }^{1}$ Vanderbilt Sports Concussion Center, Vanderbilt University School of Medicine, Nashville, Tennessee; ${ }^{2}$ Department of Psychology, Veterans Affairs Connecticut Healthcare System, West Haven, Connecticut; '3Department of Counseling, Educational Psychology and Research, The University of Memphis, Tennessee; and ${ }^{4}$ Department of Neurological Surgery, Vanderbilt University Medical Center, Nashville, Tennessee

OBJECTIVE Sport-related concussion (SRC) has become a major public health concern. Prolonged recovery after SRC, named postconcussion syndrome (PCS), has been associated with several biopsychosocial factors, yet the role of both family and personal psychiatric histories requires investigation. In a cohort of concussed high school athletes, the authors examined the role(s) of family and personal psychiatric histories in the risk of developing PCS.

METHODS A retrospective cohort study of 154 high school athletes with complete documentation of postconcussion symptom resolution or persistence at 6 weeks was conducted. PCS was defined as 3 or more symptoms present 6 weeks after SRC. Three groups were defined: 1) positive family psychiatric history and personal psychiatric history (FPH/ $\mathrm{PPH}$ ), 2) positive FPH only, and 3) negative family and personal psychiatric histories (controls). Three bivariate regression analyses were conducted: FPH/PPH to controls, FPH only to controls, and FPH/PPH to FPH. Post hoc bivariate regression analyses examined specific FPH pathologies and PCS.

RESULTS Athletes with FPH/PPH compared with controls had an increased risk of PCS $\left(\chi^{2}=8.90, p=0.018 ;\right.$ OR 5.06, $95 \% \mathrm{Cl} 1.71-14.99)$. Athletes with FPH only compared with controls also had an increased risk of PCS $\left(\chi^{2}=6.04, p=\right.$ 0.03; OR 2.52, 95\% $\mathrm{Cl} 1.20-5.30$ ). Comparing athletes with FPH/PPH to athletes with FPH only, no added PCS risk was noted $\left(\chi^{2}=1.64, p=0.247\right.$; OR 2.01, 95\% Cl 0.68-5.94). Among various FPH diagnoses, anxiety $\left(\chi^{2}=7.48, p=0.021\right.$; OR 2.99, 95\% Cl 1.36-6.49) and bipolar disorder $\left(\chi^{2}=5.13, p=0.036\right.$; OR 2.74, 95\% Cl 1.14-6.67) were significantly associated with the presence of PCS.

CONCLUSIONS Concussed high school athletes with FPH/PPH were greater than 5 times more likely to develop PCS than controls. Athletes with only FPH were over 2.5 times more likely to develop PCS than controls. Those with an FPH of anxiety or bipolar disorder are specifically at increased risk of PCS. These results suggest that not only are athletes with FPH/PPH at risk for slower recovery after SRC, but those with an FPH only-especially anxiety or bipolar disorder-may also be at risk. Overall, this study supports taking a detailed FPH and PPH in the management of SRC.

https://thejns.org/doi/abs/10.3171/2018.3.PEDS1850

KEYWORDS family psychiatric history; postconcussion syndrome; personal psychiatric history; sport-related concussion; trauma

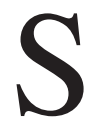
PORT-RELATED concussions (SRCs) have proven to be a major public health concern in young athletes. From the 1.6 to 3.8 million SRCs that occur each year, approximately 136,000 involve a high school athlete. ${ }^{28,42}$ While research in this area has increased in recent years, identification of biopsychosocial factors that may be important for clinical recovery, such as age, sex, and devel- opmental disabilities, has been mixed. ${ }^{15}$ Both heterogeneity and nonspecificity of symptoms used to diagnose SRCs contribute to discrepant results. ${ }^{12}$

For SRCs that occur in high school athletes, greater than $90 \%$ will have symptom resolution within 4 weeks..$^{27,28}$ Athletes with persistent symptoms beyond 4 weeks are classified as having postconcussion syndrome (PCS). PCS

ABBREVIATIONS FPH = family psychiatric history; ICD-10 = International Statistical Classification of Diseases and Related Health Problems, 10th Revision; PCS = postconcussion syndrome; $\mathrm{PPH}=$ personal psychiatric history; $\mathrm{SRC}=$ sport-related concussion.

SUBMITTED January 25, 2018. ACCEPTED March 14, 2018.

INCLUDE WHEN CITING Published online June 1, 2018; DOI: 10.3171/2018.3.PEDS1850. 
includes symptoms that affect somatic, cognitive, sleep, and emotional functioning.? The prolonged symptoms following SRC can adversely affect the athlete's academic performance, ${ }^{36}$ neurocognitive functioning, ${ }^{9}$ and exercise tolerance. ${ }^{18}$ Often, athletes with PCS suffer both personally and socially from their ongoing symptoms. At present, a consensus definition of PCS does not exist. ${ }^{37}$ PCS is defined in the Diagnostic and Statistical Manual of Mental Disorders, 4th edition (DSM-IV) ${ }^{1}$ as 3 or more symptoms lasting longer than 3 months, while the International Statistical Classification of Diseases and Related Health Problems, 10th Revision (ICD-10) ${ }^{41}$ defines PCS as 3 or more symptoms, without specifying a length of symptom duration. The diagnosis of PCS has been omitted from the DSM-V. ${ }^{2}$ Perhaps more clinically relevant, a study of more than 500 sports medicine physicians concluded that the relative majority (33\%) diagnosed PCS at 1 month, yet no true majority was found. ${ }^{37}$

Among numerous biopsychosocial factors related to PCS, including age, ${ }^{6}$ sex, ${ }^{14,32}$ early/initial symptom burden, ${ }^{17,29}$ and various acute and subacute symptoms,,${ }^{17,33}$ the importance of a psychiatric history has also been investigated. In terms of a positive personal psychiatric history $(\mathrm{PPH})$, Ellis et al. found that a personal preinjury history of depression was an independent predictor of PCS in a pediatric SRC population, ${ }^{10}$ and Morgan et al. reported that young athletes with PCS were more likely to have a $\mathrm{PPH}^{33}$ In contrast, Terwilliger et al. studied a group of young athletes with and without a recurrent head impact 24 hours after SRC and did not find a difference in length of recovery based on PPH..$^{39}$ Regarding family psychiatric history (FPH), Morgan et al. ${ }^{33}$ identified a positive FPH as more common in young athletes with PCS. In a study examining development of psychiatric illness after SRC in a pediatric population, Ellis et al. ${ }^{11}$ reported that patients with SRC who developed a postinjury psychiatric illness were more likely to have an FPH. More than $90 \%$ of patients who developed a postinjury psychiatric outcome met ICD-10 criteria for PCS. No studies have reported an absent association between FPH and recovery after SRC. ${ }^{15}$

While these studies have reported that FPH and PPH are independently associated with PCS, these factors have been studied in the context of multiple candidate variables, and their specific importance has yet to be confirmed in a dedicated study. Moreover, the role of a combined FPH and $\mathrm{PPH}(\mathrm{FPH} / \mathrm{PPH})$ has yet to be investigated as a predictor of PCS..$^{15}$ The aim of the current study was threefold: 1) to examine and replicate the previously demonstrated association between FPH and development of PCS, 2) to examine the influence of FPH/PPH on the development of PCS, and 3) to examine specific FPH pathologies in developing PCS in a high school athlete population.

\section{Methods \\ Study Design}

Institutional review board approval was obtained prior to initiation of this retrospective cohort study. Participants were high school athletes from various high schools in middle Tennessee presenting to the Vanderbilt University Sports Concussion Center for postconcussion evaluation during the years 2013-2017. Study data were collected and managed using the REDCap (Research Electronic Data Capture) electronic data capture tools hosted at Vanderbilt University. ${ }^{13}$ REDCap is a secure, web-based application designed to support data capture for research studies.

\section{Participants}

For all athletes who sustained an SRC, demographic variables and pre- and postinjury characteristics were collected using a secure electronic medical record. A suspected diagnosis of SRC was identified by a certified athletic trainer on site at the time of injury and later confirmed by a team physician in accordance with the Concussion In Sport Group guidelines. ${ }^{24}$ Study inclusion criteria were 1) age 13-18 years, 2) concussion sustained during sport, 3) presentation to the Sports Concussion Center between June 1,2013, and May 31,2017, with evaluation by a sports neuropsychologist (G.S.S.), 4) complete documentation of symptom resolution or persistence at 6 weeks, and 5) explicit documentation of presence or absence of FPH. The exclusion criterion was absent documentation of presence or absence of PPH. A total of 168 patients met study inclusion criteria, and 14 were excluded due to missing PPH data.

\section{Data Collection}

Symptoms were collected from 2 sources: 1) a self-reported 22-item postconcussion symptom scale ${ }^{20}$ administered at each clinic visit, and 2) clinical evaluation/medical record notes. PCS was defined based on the ICD-10 definition, which includes the presence of 3 or more symptoms without a defined time period. For the current study, a symptom duration of 6 weeks was chosen 1) to clearly demarcate each group, 2) to ensure that clinic scheduling and clinician availability were not factors in group assignment, and 3) because children and adolescents have been shown to take more time to recovery than adults. ${ }^{8,43}$ The 6-week operational definition of symptom duration required for assignment to the PCS group is similar to that reported in other studies, ${ }^{19,38}$ but it differs slightly from the typically used 4-week duration. ${ }^{37}$ Control patients required documentation of an absence of 3 or more symptoms and/ or a diagnostic impression indicating absence of residual SRC-related symptoms.

Presence of family and personal psychiatric histories was assessed during the postinjury clinical interview by a sports neuropsychologist (G.S.S.) and recorded as binary (present or absent). All PPHs were preexisting and not newly diagnosed at the time of concussion evaluation. Given that this was a retrospective study, the treating clinician was blinded to the purpose of the study. The parent/ guardian of each high school athlete was queried, "Do you know of any blood relative, alive or deceased, who has been diagnosed with a psychiatric disorder (anxiety, depression, bipolar disorder, schizophrenia) and treated with medicine by a doctor?" When present, known, and corroborated by an adult family member accompanying the student-athlete to the clinic, the specific psychiatric diagnosis was recorded. Family psychiatric history was considered positive in up to second-degree family members to the athlete and 
TABLE 1. Demographic characteristics of patients with an FPH/PPH, FPH only, and control groups

\begin{tabular}{|c|c|c|c|c|c|c|}
\hline Characteristic & $\mathrm{FPH} / \mathrm{PPH}(\mathrm{n}=18)$ & FPH Only $(n=59)$ & Control $(n=77)$ & F Statistic* & $\chi^{2}$ & p Value \\
\hline \multicolumn{7}{|l|}{ Demographic } \\
\hline Mean age, yrs (SD) & $15.28(1.02)$ & $14.92(1.04)$ & $14.73(1.31)$ & 1.67 & & 0.19 \\
\hline No. of males & $6(33.3 \%)$ & $38(64.4 \%)$ & $42(54.5 \%)$ & & 5.51 & 0.06 \\
\hline \multicolumn{7}{|l|}{ Medical history } \\
\hline PCS diagnosis & $11(61.1 \%)$ & $25(43.9 \%)$ & $18(23.7 \%)$ & & & \\
\hline Prior concussion & $8(44.4 \%)$ & $18(30.5 \%)$ & $26(33.8 \%)$ & & 1.2 & 0.55 \\
\hline ADHD/LD & $6(42.9 \%)$ & $6(10.3 \%)$ & $6(7.8 \%)$ & & 13.98 & $<0.01$ \\
\hline \multicolumn{7}{|l|}{ Psychiatric history } \\
\hline Anxiety & $14(77.8 \%)$ & $22(37.3 \%)$ & & & & \\
\hline Bipolar disorder & $7(38.9 \%)$ & $18(30.5 \%)$ & & & & \\
\hline Depression & $11(61.1 \%)$ & $26(44.1 \%)$ & & & & \\
\hline Other & $4(22.2 \%)$ & $17(28.8 \%)$ & & & & \\
\hline
\end{tabular}

$\mathrm{ADHD}=$ attention-deficit/hyperactivity disorder; $\mathrm{LD}=$ learning disability.

Values represent the number of patients (\%), unless otherwise indicated.

* ANOVA.

included aunts, uncles, and grandparents. Common FPH pathologies included anxiety, bipolar disorder, depression, and schizophrenia.

\section{Statistical Analysis}

The sample was divided into the following 3 groups: 1) positive FPH/PPH, 2) positive FPH only, and 3) negative family and personal psychiatric histories (controls). Oneway ANOVA tests of continuous demographic variable differences and a chi-square test of categorical demographic variables were performed to examine data differences across the 3 groups. Continuous variables are presented as the mean and standard deviation. Binary variables are presented as percentages.

Three bivariate regression analyses were conducted: 1$)$ FPH/PPH to controls, 2) FPH only to controls, and 3) FPH/ PPH to FPH only. Post hoc bivariate regression analyses examined specific FPH pathologies in all participants. Odds ratios and $95 \%$ confidence intervals were calculated using bivariate regression. In order to control for inflated type I bivariate regressions and multiple comparisons, significance levels were adjusted for multiple comparisons using the false discovery rate Benjamini-Hochberg procedure with significance set at $\mathrm{p}<0.05 .{ }^{5}$ Statistical analyses were performed using IBM SPSS Statistics (version 24, IBM Corp.).

\section{Results}

Demographic characteristics of the 3 study groups are presented in Table 1 . Of the 154 total patients included in the final analysis, 18 had a positive FPH/PPH, 59 had a positive FPH only, and 77 served as controls. Analysis of continuous demographic variables revealed no significant differences among the groups, with the exception of attention-deficit/hyperactivity disorder/learning disability (ADHD/LD), $\mathrm{F}=13.98, \mathrm{p}<0.01$, which was significantly higher in the FPH/PPH group. However, this variable was not utilized as a covariate, as it did not have a significant influence on the outcome of PCS $\left(\chi^{2}=0.48, p=0.50\right)$. Elev- en (61.1\%) FPH/PPH athletes developed PCS, 25 (43.9\%) FPH-only athletes developed PCS, and 18 (23.7\%) controls developed PCS. Prior concussion history was present in 8 (44.4\%) FPH/PPH cases, 18 (30.5\%) FPH-only cases, and $26(33.8 \%)$ controls. The three most commonly reported family psychiatric history pathologies were anxiety $(77.8 \%$ FPH/PPH cases, 37.3\% FPH-only cases), bipolar disorder (38.9\% FPH/PPH cases, 30.5\% FPH-only cases), and depression (61.1\% FPH/PPH cases, $44.1 \%$ FPH-only cases).

\section{FPH/PPH and FPH Only as Predictors of PCS}

Athletes with FPH/PPH had an increased risk of PCS $\left(\chi^{2}=8.90, p=0.018 ;\right.$ OR 5.06, 95\% CI 1.71-14.99), compared to controls (Table 2). Athletes with FPH only also had an increased risk of PCS $\left(\chi^{2}=6.04, p=0.03\right.$; OR 2.52, 95\% CI 1.20-5.30), compared with controls. The presence of $\mathrm{FPH} / \mathrm{PPH}$ did not increase athletes' risks of developing PCS above and beyond FPH only $\left(\chi^{2}=1.64, \mathrm{p}=0.247\right.$; OR $2.01,95 \%$ CI $0.68-5.94)$. Among pathologies in our entire FPH sample, anxiety $\left(\chi^{2}=7.48, \mathrm{p}<0.021\right.$; OR $2.99,95 \%$ CI 1.36-6.49) and bipolar disorder $\left(\chi^{2}=5.13, \mathrm{p}=0.036\right.$; OR $2.74,95 \%$ CI $1.14-6.67)$ were significantly associated with presence of PCS (Table 3).

\section{Discussion}

In this retrospective cohort study of high school athletes evaluated after SRC, we found that athletes with a history of both family and personal psychiatric illness (FPH/PPH) were over 5 times more likely to develop PCS. Athletes without a personal history of psychiatric illness, yet only a family history of psychiatric illness, were over 2.5 times more likely to develop PCS. Furthermore, athletes with a family history of anxiety and bipolar disorder were at greater risk for developing PCS. To our knowledge, this is the first reported study demonstrating that athletes with FPH/PPH have a compounded risk of developing PCS following SRC. The results from this study extend previous findings identifying predictors of PCS in the young athlete population ${ }^{14,17,22,32,33}$ and work investigating 
TABLE 2. Bivariate regression of PCS comparing FPH/PPH, FPH only, and control groups

\begin{tabular}{|c|c|c|c|c|c|c|c|c|}
\hline & \multirow[b]{2}{*}{$\mathrm{B}$} & \multirow[b]{2}{*}{ SE } & \multirow[b]{2}{*}{ Wald } & \multirow[b]{2}{*}{ p Value } & \multirow{2}{*}{$\begin{array}{l}\text { Adjusted } \\
\text { p Value* }\end{array}$} & \multirow[b]{2}{*}{ OR } & \multicolumn{2}{|c|}{$95 \% \mathrm{Cl}$} \\
\hline & & & & & & & Lower Bound & Upper Bound \\
\hline FPH/PPH \& controls $\dagger$ & 1.62 & 0.55 & 8.58 & $<0.01$ & 0.018 & 5.06 & 1.71 & 14.99 \\
\hline FPH only \& controlsł & 0.92 & 0.38 & 5.92 & 0.02 & 0.03 & 2.52 & 1.20 & 5.30 \\
\hline FPH/PPH \& FPH only§ & 0.70 & 0.55 & 1.60 & 0.21 & 0.247 & 2.01 & 0.68 & 5.94 \\
\hline
\end{tabular}

Boldface type indicates statistical significance.

* Adjusted $p$ values for multiple comparisons using the false discovery rate Benjamini-Hochberg procedure.

$\dagger$ Bivariate regression of overall model, $\chi^{2}=8.90, p<0.01$, Nagelkerke $R^{2}=0.13$.

$\ddagger$ Bivariate regression of overall model, $\chi^{2}=6.04, p=0.02$, Nagelkerke $R^{2}=0.06$.

$\S$ Bivariate regression of overall model, $\chi^{2}=1.64, p=0.21$, Nagelkerke $R^{2}=0.03$.

the role of psychiatric history in prolonged recovery after an SRC. $3,10,11,21,33$

This study provides additional evidence of FPH only as a predictor of PCS and identifies high school athletes with $\mathrm{FPH} / \mathrm{PPH}$ as also having an increased risk of PCS. Both of these findings are consistent with literature identifying $\mathrm{FPH}^{33}$ and $\mathrm{PPH}^{10}$ as independent predictors of PCS. While routine SRC management includes an assessment of PPH, FPH is less commonly obtained. These results provide support for FPH to be part of routine SRC assessment and management, even in athletes with no personal history of any psychological or psychiatric diagnosis. In areas with limited access to a concussion specialist, primary care providers may be less likely to record a family or personal psychiatric history. In a survey of 367 primary care providers, over $30 \%$ stated that they did not routinely use published guidelines in concussion management, with unawareness of the guidelines cited as the most common reason for lack of use. ${ }^{35}$ In addition, only $16 \%$ of these providers had access to neuropsychological testing within 1 week of injury. ${ }^{35}$ This further suggests that concussion management, in particular by nonspecialists, does not include documentation of psychiatric histories as part of routine assessment and care. However, its potential relevance is underscored, given the 5-times and 2.5-times increased odds in PCS diagnosis in compounded FPH/PPH and FPH-only cases, respectively.

In the FPH pathologies that were recorded in both the FPH-only and FPH/PPH groups (all FPH pathologies), anxiety and bipolar disorder were significantly associated with the development of PCS. These two conditions are particularly important because of their high heritability. For example, one study estimated that children of parents with a diagnosed anxiety disorder have a greater than 7 times risk of personally developing an anxiety disorder. ${ }^{40}$ Similarly for bipolar disorder, studies have estimated its heritability in excess of $80 \% .{ }^{25}$ Moreover, the prevalence of these disorders in high school students is approximately $32 \%$ for anxiety and $4 \%$ for bipolar disorder. ${ }^{30}$ In the context of the high heritability of these two disorders, family histories of psychiatric illness with a particular emphasis on anxiety and bipolar disorder may further identify athletes at risk of prolonged recovery post-SRC.

Armed with this information, how can athletes with FPH/PPH or FPH only be treated to minimize the risk of PCS? One possibility involves specialized educational, athletic, and medical accommodations for these athletes.
Although findings have been mixed in evaluating the effectiveness of complete rest, ${ }^{26} 1$ week of full cognitive and physical rest in athletes who were slow to recover demonstrated substantial improvement in $62 \%$ of the cohort studied ${ }^{34}$ It remains to be seen whether extended rest immediately postinjury is protective against the development of PCS in athletes with a positive FPH/PPH or FPH only. A second possibility for more specialized treatment of PCS in FPH/PPH or FPH-only athletes is for more frequent and multidisciplinary clinical follow-up after SRC. One study ${ }^{21}$ demonstrated a benefit of using a collaborative care approach involving cognitive-behavioral therapy, psychopharmacological treatment, and care coordination among a multidisciplinary team of health care providers and school officials. After 6 months of treatment, high postconcussive symptom levels were reported in $13 \%$ of the collaborative care group compared with $40 \%$ of controls. A final possible treatment strategy may be pharmacological management; however, there is a lack of clear guidelines for use of medications in managing recovery after SRC, and limited evidence exists for their effectiveness. ${ }^{23}$ Although we did not examine the pharmacological and/or counseling treatments for athletes with psychiatric illness, further study is warranted to understand how FPH/PPH and FPH-only athletes may benefit from pharmacological and/or counseling interventions. Additionally, these studies may describe the relationship between treated and untreated psychiatric illness and an association with development of PCS.

Lastly, the importance of psychiatric history may be relevant to the discussion of "brain reserve" and outcomes after concussion. Bernard et al. found that in a non-SRC population of concussed children 2-12 years of age, preexisting noninjury factors had an increasingly strong association with PCS after a mild traumatic brain injury over time. ${ }^{6}$ Prior arguments for brain reserve as a modifying factor in outcomes after cerebral insult have centered around poorer outcomes for children with preexisting learning difficulties. ${ }^{6}$ In the current study, we found that learning disabilities were significantly more common in the combined FPH/PPH group, suggesting that a relationship may exist among learning disability, FPH/PPH, and PCS. It is possible the concept of brain reserve is intertwined with a genetic component underlying the development of PCS in a similar manner to APOE $\varepsilon 4$-positive athletes reporting greater symptomatology postconcussion than APOE ع4-negative athletes. ${ }^{31}$ Overall, it is unclear how psychiatric illness and learning disabilities interact to modify an 
TABLE 3. Bivariate regression of PCS comparing specific FPH diagnoses and controls

\begin{tabular}{|c|c|c|c|c|c|c|c|c|}
\hline \multirow[b]{2}{*}{$\mathrm{FPH}$} & \multirow[b]{2}{*}{ B } & \multirow[b]{2}{*}{ SE } & \multirow[b]{2}{*}{ Wald } & \multirow[b]{2}{*}{ p Value } & \multirow{2}{*}{$\begin{array}{l}\text { Adjusted } \\
\text { p Value* }\end{array}$} & \multirow[b]{2}{*}{ OR } & \multicolumn{2}{|c|}{$95 \% \mathrm{Cl}$} \\
\hline & & & & & & & Lower Bound & Upper Bound \\
\hline Anxiety $†$ & 1.09 & 0.40 & 7.39 & $<0.01$ & 0.021 & 2.99 & 1.36 & 6.49 \\
\hline Bipolar disorderf & 1.01 & 0.44 & 5.09 & 0.02 & 0.036 & 2.74 & 1.14 & 6.67 \\
\hline Depression§ & 0.42 & 0.39 & 1.17 & 0.28 & 0.276 & 1.52 & 0.71 & 3.25 \\
\hline
\end{tabular}

Boldface type indicates statistical significance.

* Adjusted $p$ values for multiple comparisons using the false discovery rate Benjamini-Hochberg procedure.

$\dagger$ Bivariate regression of overall model, $\chi^{2}=7.48, p<0.01$, Nagelkerke $R^{2}=0.06$.

$\ddagger$ Bivariate regression of overall model, $\chi^{2}=5.13, p=0.02$, Nagelkerke $R^{2}=0.05$.

$\S$ Bivariate regression of overall model, $\chi^{2}=1.17, p=0.28$, Nagelkerke $R^{2}=0.01$.

individual student-athlete's response to SRC, yet brain reserve may be decreased in both conditions, thus inhibiting recovery.

\section{Limitations}

We acknowledge several limitations to the results of our study. Utilization of ICD-10 criteria for PCS diagnosis can be limited by a $40 \%$ false-positive rate. ${ }^{16}$ In addition, individuals with medical illnesses, orthopedic injuries, alcohol use, and exercise exertion may report PCS-like symptoms. ${ }^{4}$ It may be difficult for high school student-athletes to differentiate symptoms specific to the SRC versus the symptoms of daily life. Moreover, our selection of participants may be at risk of selection bias. We chose a convenience sample referred to a specialty sports concussion clinic, and this could limit the generalizability of our findings. A potential recall bias may have been present when ascertaining preinjury factors that defined an athlete's family and personal health history. Finally, our results indicate a potential compounding effect of having both a family and personal psychiatric history in PCS development when compared with controls. While the direct comparison between the two groups was not statistically significant, further study is needed to understand the prognostic importance and risk relationship between having an FPH only and having both an FPH and a PPH.

\section{Conclusions}

In this retrospective cohort study, we found that high school athletes with FPH/PPH were over 5 times more likely to develop PCS than controls. Athletes with FPH only were over 2.5 times more likely to develop PCS compared to controls. Athletes with a family history of anxiety or bipolar disorder were more likely to develop PCS compared to other diagnoses of FPH studied (i.e., depression or schizophrenia). These results confirm prior findings of FPH as a potential predictor of PCS and identify FPH/PPH as a novel predictor of PCS. Athletes without a personal psychiatric history but rather a family psychiatric history only may also be at risk of PCS, and athletes with both a family and personal psychiatric history may have a compounded risk of PCS. Finally, these results support taking a detailed family and personal psychiatric history in the management of SRC and PCS.

\section{References}

1. American Psychiatric Association: Diagnostic and Statistical Manual of Mental Disorders, ed 4. Washington, DC: American Psychiatric Association, 2000

2. American Psychiatric Association: Diagnostic and Statistical Manual of Mental Disorders, ed 5. Washington, DC: American Psychiatric Association, 2013

3. Asken BM, McCrea MA, Clugston JR, Snyder AR, Houck ZM, Bauer RM: "Playing through it": delayed reporting and removal from athletic activity after concussion predicts prolonged recovery. J Athl Train 51:329-335, 2016

4. Balasundaram AP, Athens J, Schneiders AG, McCrory P, Sullivan SJ: the influence of psychological and lifestyle factors on the reporting of postconcussion-like symptoms. Arch Clin Neuropsychol 31:197-205, 2016

5. Benjamini Y, Hochberg Y: Controlling the false discovery rate: a practical and powerful approach to multiple testing. $\mathbf{J}$ R Stat Soc Ser A Stat Soc 57:289-300, 1995

6. Bernard CO, Ponsford JA, McKinlay A, McKenzie D, Krieser D: Predictors of post-concussive symptoms in young children: injury versus non-injury related factors. J Int Neuropsychol Soc 22:793-803, 2016

7. Blume H, Hawash K: Subacute concussion-related symptoms and postconcussion syndrome in pediatrics. Curr Opin Pediatr 24:724-730, 2012

8. Cassidy JD, Cancelliere C, Carroll LJ, Côté P, Hincapié CA, Holm LW, et al: Systematic review of self-reported prognosis in adults after mild traumatic brain injury: results of the International Collaboration on Mild Traumatic Brain Injury Prognosis. Arch Phys Med Rehabil 95 (3 Suppl):S132S151, 2014

9. Crowe L, Collie A, Hearps S, Dooley J, Clausen H, Maddocks D, et al: Cognitive and physical symptoms of concussive injury in children: a detailed longitudinal recovery study. Br J Sports Med 50:311-316, 2016

10. Ellis MJ, Cordingley DM, Vis S, Reimer KM, Leiter J, Russell K: Clinical predictors of vestibulo-ocular dysfunction in pediatric sports-related concussion. J Neurosurg Pediatr 19:38-45, 2017

11. Ellis MJ, Ritchie LJ, Koltek M, Hosain S, Cordingley D, Chu $\mathrm{S}$, et al: Psychiatric outcomes after pediatric sports-related concussion. J Neurosurg Pediatr 16:709-718, 2015

12. Feddermann-Demont N, Echemendia RJ, Schneider KJ, Solomon GS, Hayden KA, Turner M, et al: What domains of clinical function should be assessed after sport-related concussion? A systematic review. Br J Sports Med 51:903-918, 2017

13. Harris PA, Taylor R, Thielke R, Payne J, Gonzalez N, Conde JG: Research electronic data capture (REDCap) - a metadata-driven methodology and workflow process for providing translational research informatics support. J Biomed Inform 42:377-381, 2009 
14. Heyer GL, Schaffer CE, Rose SC, Young JA, McNally KA, Fischer AN: specific factors influence postconcussion symptom duration among youth referred to a sports concussion clinic. J Pediatr 174:33-38.e2, 2016

15. Iverson GL, Gardner AJ, Terry DP, Ponsford JL, Sills AK, Broshek DK, et al: Predictors of clinical recovery from concussion: a systematic review. Br J Sports Med 51:941-948, 2017

16. Kashluba S, Casey JE, Paniak C: Evaluating the utility of ICD-10 diagnostic criteria for postconcussion syndrome following mild traumatic brain injury. J Int Neuropsychol Soc 12:111-118, 2006

17. Kerr ZY, Zuckerman SL, Wasserman EB, Vander Vegt CB, Yengo-Kahn A, Buckley TA, et al: Factors associated with post-concussion syndrome in high school student-athletes. J Sci Med Sport 21:447-452, 2018

18. Kozlowski KF, Graham J, Leddy JJ, Devinney-Boymel L, Willer BS: Exercise intolerance in individuals with postconcussion syndrome. J Athl Train 48:627-635, 2013

19. Leddy JJ, Kozlowski K, Donnelly JP, Pendergast DR, Epstein LH, Willer B: A preliminary study of subsymptom threshold exercise training for refractory post-concussion syndrome. Clin J Sport Med 20:21-27, 2010

20. Lovell MR, Iverson GL, Collins MW, Podell K, Johnston KM, Pardini D, et al: Measurement of symptoms following sports-related concussion: reliability and normative data for the post-concussion scale. Appl Neuropsychol 13:166-174, 2006

21. McCarty CA, Zatzick D, Stein E, Wang J, Hilt R, Rivara FP: Collaborative care for adolescents with persistent postconcussive symptoms: a randomized trial. Pediatrics 138:138, 2016

22. McCrea M, Guskiewicz K, Randolph C, Barr WB, Hammeke TA, Marshall SW, et al: Incidence, clinical course, and predictors of prolonged recovery time following sport-related concussion in high school and college athletes. J Int Neuropsychol Soc 19:22-33, 2013

23. McCrory P, Meeuwisse W, Dvořák J, Aubry M, Bailes J, Broglio S, et al: Consensus statement on concussion in sport-the 5th International Conference On Concussion in Sport held in Berlin, October 2016. Br J Sports Med 51:838-847, 2017

24. McCrory P, Meeuwisse WH, Aubry M, Cantu B, Dvorák J, Echemendia RJ, et al: Consensus statement on concussion in sport: the 4th International Conference on Concussion in Sport held in Zurich, November 2012. Br J Sports Med 47:250-258, 2013

25. McGuffin P, Rijsdijk F, Andrew M, Sham P, Katz R, Cardno A: The heritability of bipolar affective disorder and the genetic relationship to unipolar depression. Arch Gen Psychiatry 60:497-502, 2003

26. McLeod TC, Lewis JH, Whelihan K, Bacon CE: Rest and return to activity after sport-related concussion: a systematic review of the literature. J Athl Train 52:262-287, 2017

27. Meehan WP III, d'Hemecourt P, Collins CL, Comstock RD: Assessment and management of sport-related concussions in United States high schools. Am J Sports Med 39:23042310, 2011

28. Meehan WP III, d'Hemecourt P, Comstock RD: High school concussions in the 2008-2009 academic year: mechanism, symptoms, and management. Am J Sports Med 38:24052409, 2010

29. Meehan WP III, Mannix R, Monuteaux MC, Stein CJ, Bachur RG: Early symptom burden predicts recovery after sport-related concussion. Neurology 83:2204-2210, 2014

30. Merikangas KR, He JP, Burstein M, Swanson SA, Avenevoli $\mathrm{S}$, Cui L, et al: Lifetime prevalence of mental disorders in U.S. adolescents: results from the National Comorbidity Survey Replication-Adolescent Supplement (NCS-A). J Am Acad Child Adolesc Psychiatry 49:980-989, 2010
31. Merritt VC, Arnett PA: Apolipoprotein E (APOE) $\varepsilon 4$ allele is associated with increased symptom reporting following sports concussion. J Int Neuropsychol Soc 22:89-94, 2016

32. Miller JH, Gill C, Kuhn EN, Rocque BG, Menendez JY, O'Neill JA, et al: Predictors of delayed recovery following pediatric sports-related concussion: a case-control study. J Neurosurg Pediatr 17:491-496, 2016

33. Morgan CD, Zuckerman SL, Lee YM, King L, Beaird S, Sills AK, et al: Predictors of postconcussion syndrome after sports-related concussion in young athletes: a matched casecontrol study. J Neurosurg Pediatr 15:589-598, 2015

34. Moser RS, Schatz P, Glenn M, Kollias KE, Iverson GL: Examining prescribed rest as treatment for adolescents who are slow to recover from concussion. Brain Inj 29:58-63, 2015

35. Pleacher MD, Dexter WW: Concussion management by primary care providers. Br J Sports Med 40:e2, 2006

36. Ransom DM, Vaughan CG, Pratson L, Sady MD, McGill CA, Gioia GA: Academic effects of concussion in children and adolescents. Pediatrics 135:1043-1050, 2015

37. Rose SC, Fischer AN, Heyer GL: How long is too long? The lack of consensus regarding the post-concussion syndrome diagnosis. Brain Inj 29:798-803, 2015

38. Tator CH, Davis HS, Dufort PA, Tartaglia MC, Davis KD, Ebraheem A, et al: Postconcussion syndrome: demographics and predictors in 221 patients. J Neurosurg 125:1206-1216, 2016

39. Terwilliger VK, Pratson L, Vaughan CG, Gioia GA: Additional post-concussion impact exposure may affect recovery in adolescent athletes. J Neurotrauma 33:761-765, 2016

40. Turner SM, Beidel DC, Costello A: Psychopathology in the offspring of anxiety disorders patients. J Consult Clin Psychol 55:229-235, 1987

41. World Health Organization: International Statistical Classification of Diseases and Related Health Problems, ed 10. Geneva: World Health Organization, 1992

42. Zuckerman SL, Kerr ZY, Yengo-Kahn A, Wasserman E, Covassin T, Solomon GS: Epidemiology of sports-related concussion in NCAA athletes from 2009-2010 to 2013-2014: incidence, recurrence, and mechanisms. Am J Sports Med 43:2654-2662, 2015

43. Zuckerman SL, Lee YM, Odom MJ, Solomon GS, Forbes JA, Sills AK: Recovery from sports-related concussion: Days to return to neurocognitive baseline in adolescents versus young adults. Surg Neurol Int 3:130, 2012

\section{Disclosures}

G. S. Solomon is a consultant for the Nashville Predators, Tennessee Titans, and the athletic departments of Tennessee Tech University and the University of Tennessee, fees paid to institution. $\mathrm{He}$ is also a consultant to the National Football League Department of Health and Safety.

\section{Author Contributions}

Conception and design: Zuckerman, Legarreta, Solomon. Acquisition of data: Legarreta. Analysis and interpretation of data: all authors. Drafting the article: Zuckerman, Legarreta, Brett. Critically revising the article: all authors. Reviewed submitted version of manuscript: all authors. Approved the final version of the manuscript on behalf of all authors: Zuckerman. Statistical analysis: Zuckerman, Legarreta, Brett. Administrative/technical/ material support: Zuckerman, Solomon. Study supervision: Zuckerman, Solomon.

\section{Correspondence}

Scott L. Zuckerman: Vanderbilt University Medical Center, Nashville, TN. scott.zuckerman@vumc.org. 